\title{
Mercantilización en las políticas de inclusión al trabajo: una aproximación desde las experiencias
}

\author{
Commercialization in labor inclusion policies: \\ an approach from experiences
Mercantilização nas políticas de inclusão no trabalho: uma abordagem a partir das experiências

Emilio Seveso*

\section{RESUMEN}

Durante las últimas décadas, los formatos de asistencia condicional muestran una expansión significativa en América Latina. Fundados en actividades no cualificadas y de vinculación precaria, su retórica humanitaria tiende a desdibujar las consecuencias que implican las prácticas de corresponsabilidad y, ante todo, las renovadas relaciones entre el Estado y el mercado que, por diversas vías, valorizan procesos productivos y comerciales. En este artículo recuperamos las vivencias y expresiones de un conjunto de beneficiarios con el fin de indagar las tendencias de mercantilización asociadas a tales iniciativas. En particular, nos interesan tres dimensiones: la expropiación de la vitalidad corporal vía la valorización del capital humano, la circulación monetaria promovida mediante la aplicación de los programas y la desposesión lograda mediante la convergencia de créditos para el consumo; tres aspectos que impugnan los preceptos de autodeterminación, libertad y bienestar formalmente postulados. En torno a las tendencias de modernización e innovación gubernamental promovidas en la región, el sitio de la experiencia nos
Palabras

clave: cuerpo, experiencia, inclusión social, políticas sociales, trabajo.

* Doctor en Estudios Sociales de América Latina por la Universidad Nacional de Córdoba (Argentina). Investigador Asistente del Consejo Nacional de Investigaciones Científicas y Técnicas (CONICET). Profesor Adjunto Responsable de "Sociología de la Educación" en la Facultad de Ciencias Humanas de la Universidad Nacional de San Luis, San Luis, Argentina. Integrante del Programa "Ideología, prácticas sociales y conflicto" (IECET-CONICET). Dirección de E-mail: emilioseveso@hotmail.com 
permite profundizar en el vínculo entre las actuales condiciones estructurales de pobreza, las estrategias de regulación progresista del Estado y la transversalidad de las tendencias mercantiles. Desde allí, abrimos dimensiones analíticas para reflexionar sobre los mecanismos de regulación que son impuestos a las clases subalternas bajo presumibles condiciones de inclusión social. En las conclusiones señalamos que la circulación comercial y financiera es favorecida "desde abajo" mediante la doble figura de trabajadores activos y consumidores sagaces. Mientras tanto, indicamos que existe un efecto operado "desde arriba", ya que, frente a la desigualdad y la opresión entre clases sociales, las políticas escenifican los derechos de ciudadanía que encubren la activa regulación de las experiencias.

\begin{abstract}
During the last decades, conditional assistance formats show a significant expansion in Latin America. Based on unskilled activities and precarious ties, humanitarian rhetoric tends to blur the consequences of co-responsibility practices and, above all, the renewed relations between the State and the market through various means, value-productive and commercial processes. In this article, we recover the experiences and expressions of a group of beneficiaries to investigate commercialization trends associated with such initiatives. We are interested in three dimensions: the appropriation of bodily vitality through the valorization of human capital, monetary circulation promoted through the application of programs, and dispossession achieved through the convergence of credits for consumption- three aspects that challenge the proposed precepts of self-determination, freedom, and welfare. Regarding the trends of government modernization and innovation promoted in the region, the "site of experience" allows us to deepen the link between the current structural conditions of poverty, the strategies of progressive regulation of the State, and the transversality of market trends. From there, we open analytical dimensions to reflect on the regulatory mechanisms imposed on subordinate classes under presumed conditions of social inclusion. In conclusion, we point out that commercial/financial circulation is favored "from below" through the double figure of active workers and shrewd consumers. Meanwhile, we indicate an effect operated "from above" since, in the face of inequality and oppression between social classes, policies stage the rights of citizenship that cover up the active regulation of experiences.
\end{abstract}

Keywords: body, experience, social inclusion, social policies, work. 


\section{RESUMO}

Durante as últimas décadas, os formatos de assistência condicional mostram uma significativa expansão na América Latina. Com base em atividades não qualificadas e de vinculação precária, sua retórica humanitária tende a obscurecer as consequências Palavras-chave: corpo, experiência, inclusão social, implicadas nas práticas de corresponsabilidade e, sobretudo, nas renovadas relações entre o Estado e o mercado que, através de vários canais, valorizam os processos produtivos e comerciais. Neste artigo recuperamos as vivências e expressões de um grupo de beneficiários a fim de investigar as tendências de mercantilização associadas a tais iniciativas. Em particular, estamos interessados em três dimensões: a expropriação da vitalidade corporal através da valorização do capital humano, a circulação monetária promovida mediante a aplicação dos programas e a despossessão alcançada através da convergência de créditos para o consumo; três aspectos que impugnam os preceitos formalmente postulados de autodeterminação, liberdade e bem-estar. Com relação às tendências de modernização e inovação governamental promovidas na região, o "local da experiência" nos permite aprofundar na ligação entre as atuais condições estruturais de pobreza, as estratégias de regulamentação progressista do Estado e a transversalidade das tendências mercantis. A partir daí, abrimos dimensões analíticas para refletir sobre os mecanismos regulatórios impostos às classes subordinadas sob presumíveis condições de inclusão social. Nas conclusões apontamos que a circulação comercial/financeira é favorecida "desde abaixo" através da dupla figura de trabalhadores ativos e consumidores sagazes. Entretanto, indicamos que existe um efeito operado "de cima", pois, diante da desigualdade e da opressão entre as classes sociais, as políticas encenam os direitos de cidadania que ocultam a ativa regulação das experiências. 


\section{Introducción al problema}

Dentro de lo que suele ser referido generalmente como "el mundo del trabajo", las tendencias productivas de América Latina ponen actualmente en conflicto a la integración de amplias capas poblacionales. Como resultado de las renovadas políticas neoliberales aplicadas en la mayoría de los países -y del efecto producido por los ciclos económicos de los mercados internacionales-, asistimos a la configuración de un mercado laboral fuertemente segmentado y caracterizado por la masividad del desempleo y la informalidad, combinado con situaciones de sobreempleo y subempleo. De hecho, tras los avances significativos logrados hasta mediados de la década de 2000, los mercados de trabajo se han deteriorado en general y las brechas ocupacionales se sostienen (e incluso profundizan) para casi todos los sectores (CEPAL \& OIT, 2019). Frente a esta tendencia, las iniciativas estatales de empleabilidad y formación laboral han adquirido un peso progresivo, siendo articuladas con procesos de modernización e innovación de políticas sociales que tienen como uno de sus centros a los programas temporales de trabajo.

En Argentina, en particular, esto ha sido acompañado de un prolífero debate sobre la singularidad y novedad de las medidas adoptadas. Las interrogantes fundamentales se han establecido en torno a las condiciones de aplicación de las iniciativas, sus alcances posibles y las limitaciones que poseen, verificando resultados contrapuestos sobre las dimensiones analíticas observadas. En este trabajo, más allá de los quantum de cobertura que son priorizados desde la opinión pública, buscamos complejizar el debate reconociendo el lugar específico de los sujetos afectados, apuntando a las consecuencias de las políticas sobre las tramas cotidianas, vinculares y subjetivas antes que a las líneas o índices estadísticos que pretenden evaluarlas. Concretamente, proponemos abordar las experiencias de un subconjunto de beneficiarios que integran la principal política de protección social que, desde el año 2003, es ejecutada en la provincia de San Luis. Nos referimos al Subprograma Concertación con la Comunidad (SCC) -pieza clave del denominado Plan de Inclusión Social (PIS)-, que orienta a sus 'protectores' o 'concertadores' (según la nominación recibida en diferentes etapas de ejecución) hacia la prevención del delito y la reducción de la sensación de inseguridad. Como parte del formato de correspon- 
sabilidad que aplica, las capacidades disponibles de los sujetos (identificados oficialmente como desocupados y en situación de pobreza) son activamente utilizadas para sustentar la vigilancia pública, con un impacto específico sobre la circulación de capitales y los activos financieros locales.

Esta política masiva (aunque no universal) permite poner en discusión las tendencias actuales de la inclusión al mercado de trabajo en la región. En condiciones sociales en las que la figura del empleo tradicional (universal, colectivizado y protegido) se ha desmoronado como institución neurálgica del proceso productivo y los sectores subalternos se sumergen en un estado de precariedad creciente, nos encontramos con políticas de este tipo que actualizan el modelo característico del workfare para América Latina. En ellas, se conecta desde la esfera estatal la ampliación de mecanismos de regulación de la pobreza con iniciativas de inclusión al mercado productivo y un particular interés por el impacto en el consumo. Esto forma parte de un escenario conflictivo que hemos estado explorando desde hace tiempo, apelando a la dimensión de la experiencia que permite comprender las consecuencias biopolíticas que traman la regulación de la pobreza desde la dualidad protección social/protección urbana.

Dos interrogantes nos permiten aquí establecer un primer recorte problemático y guiar nuestra argumentación. ¿Cómo se dispone la mercantilización de los cuerpos en función de los mecanismos propiciados por el programa de empleo bajo estudio? ¿Qué consecuencias tiene para los estados de pensamiento y sentimiento de los beneficiarios? A partir de estas preguntas buscamos reconocer la trama entre protecciones sociales y dinámicas mercantiles bajo particulares condiciones de expulsión, atendiendo tanto a la dimensión áspera y material de las políticas sociales como también a la dimensión sensible, expresiva y práctica de los sujetos afectados por ellas. Esto nos permitirá caracterizar ciertos rasgos de lo que emerge como singular en los nuevos programas de inclusión al mundo del trabajo, llevándonos a comprender con mayor detenimiento -más allá de la retórica humanitaria escenificada- porqué son hoy una de las vías escogidas para gestionar la desocupación y la pobreza en América Latina.

En la primera sección contextualizamos brevemente la situación del mercado de trabajo en Argentina, así como la relevancia de las po- 
líticas de inclusión al mundo del trabajo. Seguidamente, exploramos la noción de experiencia como centro analítico que nos permite abordar las expresiones de los beneficiarios. En la segunda sección avanzamos sobre el impacto de la política sobre las trayectorias, señalando su relación con las tendencias de capitalización corporal y de mercantilización de la vida cotidiana. Finalmente, en las conclusiones, especificamos el papel de las políticas para los procesos de producción y circulación de capitales, cuya trama eslabona una cadena de expropiación de energías sociales y de regulación activa.

\section{Puntualización analítica sobre políticas y experiencias}

Hacia finales de la década de los 80, en la mayoría de los países de América Latina aún prevalecía una perspectiva de derechos relativa al empleo formal y estable, especialmente disputada por colectivos sindicales y partidos de trabajadores. En la actualidad, por otro lado, asistimos a la sedimentación del trabajo precario y flexible como factor del mercado productivo, solventado en parte por las propias políticas de protección estatal. Mientras se extinguen las trayectorias de empleo para toda la vida (Sennett, 2012) y se impone la adaptabilidad como regla contractual, salarial y funcional (Campos \& Martínez Soul, 2014), emergen procesos de formación para el trabajo y de atención subsidiaria a lo largo de la vida orientadas a desarrollar destrezas asociadas a las demandas contingentes del mercado laboral (Farné, 2016). En su dimensión discursiva, esto converge con un "nuevo pacto social" que se asienta en el precepto, pretendidamente común, de que el mercado de trabajo es la "llave maestra' para la igualdad", es decir, "eje de la integración social, una fuente de sentido para la vida personal y un espacio para la participación ciudadana" (Weller, 2017, p. 9). El principio de esta asociación se materializa de facto, aunque no exclusivamente, en la vigencia de políticas de corresponsabilidad y contrapartida que apuntan a los sectores desempleados, desocupados y en situación de pobreza, requiriendo procesos de capitalización/valorización de energías para la formación de recursos humanos potenciales ${ }^{1}$. El sustento

1 En distancia a los objetivos de cobertura sobre necesidades básicas y situaciones de emergencia, la estrategia de contraprestación y condicionalidad está estructurada desde un doble objetivo. En el corto plazo, procura aliviar las situaciones de pobreza/ 
"científico" de estas iniciativas parte de numerosos enfoques hegemónicos, incluyendo versiones enriquecidas de las teorías de la marginalidad y la exclusión, de las capacidades y los funcionamientos, de la vulnerabilidad y del capital social, que resignifican faltas como recursos valorizables (Seveso, 2014).

En el caso de los programas ejecutados en Argentina durante los últimos 20 años, los diagnósticos señalan efectos multidimensionales e incluso contrapuestos, pero en general favorables para la población. La atención a los sectores de menores recursos y mayor vulnerabilidad ha sido considerada clave para reforzar los viejos y nuevos derechos sociales con impactos específicos sobre la brecha de ingresos, las tasas de pobreza e indigencia, los niveles de empleo y la estabilización del consumo, que redundan en mejor protección y seguridad social (Kessler, 2014; Lombardía \& Rodríguez, 2015). Estas miradas estructurales, sin embargo, revelan muy poco sobre la implicancia de las políticas sociales sobre la esfera del trabajo y menos aún descubren sus consecuencias para la vida cotidiana. En el contexto de sociedades crecientemente polarizadas y fragmentadas, los programas interpelan activamente a los sujetos en particular y a la sociedad en general desde un acervo de sentido asociado a las ideas de libertad, bienestar y autodeterminación. La noción de inclusión es, de hecho, un epicentro discursivo, una pieza ideológica del nuevo consenso interpretativo que escenifica la vigencia de medidas progresistas. Es precisamente en esta línea que el Plan de Inclusión Social, en el que se inserta el subprograma estudiado, plantea como objetivo la reinserción en el mercado de trabajo mediante la inclusión de la política "todos los puntanos, evitando cualquier situación injusta de exclusión social” ${ }^{2}$. De hecho, en forma explícita, la normativa señala que los beneficios salariales son la materialización de un "[i]ngreso que se gana trabajando", "evitando dar

indigencia cubriendo el umbral mínimo de necesidades a partir de las transferencias otorgadas (monetarias o en especie). Entre tanto, plantea una perspectiva de mediano a largo plazo, en tanto la contrapartida es entendida como medio capaz de potenciar ciertas capacidades disponibles. Estos supuestos parten de un vínculo de corresponsabilidad asimétricamente estructurado entre las partes: la contraprestación, pautada por el benefactor, es condición necesaria para que el beneficiario reciba los activos.

2 Puntano es el gentilicio para el topónimo San Luis, la ciudad capital de la provincia homónima. 
simplemente un subsidio, ya que este no cumple con el objetivo de la inclusión" (Suárez Godoy, 2004, pp. 35-38).

Como parte de esta lógica, se actualiza de manera eufemística el programa neoliberal para la región a partir del workfare estatal (concepto que aquí entendemos según los términos de Wacquant, 2007, 2010), con al menos dos consecuencias a resaltar. Por un lado, al gestionar las condiciones vitales y de existencia de los sujetos, la cobertura salarial inmediata compensa el impacto del orden de expulsión y regula las situaciones de conflictividad potencial. Esto se deriva del objetivo de corto plazo de los programas, cuyas transferencias (monetarias o en especies) apuntan a cubrir el umbral de necesidades mínimas de pobreza/indigencia. Entre tanto, el propósito de mediano a largo plazo demanda al sujeto una contraprestación activa, corresponsable y condicional, un involucramiento directo capaz de desarrollar activos o capitales disponibles. Desde este lugar, la ingeniería social (re)interpreta las "faltas" de la pobreza como propiedades de alcance económico y como activos susceptibles de mercantilización: a las disposiciones de trabajo informal como capital humano; a los vínculos cotidianos como capital social; y/o a la precariedad habitacional como patrimonio, entre otras iniciativas.

En relación con esta doble lógica, y en concurrencia con el proceso de acumulación general, es posible observar que los programas tienden a dinamizar parcialmente al mercado productivo y de consumo en función de formatos de trabajo precarizado. La instancia de corresponsabilización, que vuelve al sujeto un activo de la asistencia, demanda un gasto calórico/energético como condición resolutiva de la falta socioeconómica y es este plus de acción el que funda el mecanismo regular de acceso al consumo como noción restrictiva del derecho ciudadano. De este modo, en distancia a las iniciativas de cobertura que pertenecieron al paquete del denominado Consenso de Washington, los programas de trabajo son entendidos como políticas de segunda generación que promueven la batalla contra la exclusión mediante el fortalecimiento del capital social y las "cualidades activas de los pobres" (Álvarez Leguizamón, 2001). Sobre este punto, el Plan de Inclusión Social se autodefine como "una respuesta colosal a los síntomas de exclusión que aquejaban a la sociedad puntana" (Suárez Godoy, 2004, p.35). Proyecta, sobre ello, la "redistribución 
del ingreso, haciendo recaer la mayor parte del mismo en los sectores más desprotegidos y generando un círculo virtuoso a partir de la incorporación de un gran número de individuos al consumo" (Suárez Godoy, 2004, p.37). Repetidamente, es importante destacar aquí que la base de la política es "[1] a existencia de un trabajo remunerado (...) específico, en un sitio determinado y con un horario prefijado a cumplir" (Suárez Godoy, 2004, p.38). Hablamos de un recurso de subsistencia que está ligado a la condición potencial del ser-sujeto en el mercado, independientemente de las condiciones y canales precarizados por los que ello se realice.

Dentro de este esquema, la noción de inclusión social puede ser reinterpretada como fragmento de una retórica que vertebra ideológicamente la regulación de los programas vigentes. Tratamos con una red discursiva cuyos trópos (juicios y razonamientos) están orientados a persuadir y provocar respuestas cognitivas y afectivas específicas, y poniendo en juego esquemas de percepción, sentimiento y acción que demarcan lo pensable/impensable y lo posible/imposible desde su articulación en un nivel ideológico (Žižek, 1999). El discurso del bienestar social y de la libertad individual -anclados ante todo a la noción de derechos humanos- son, por ejemplo, piezas de esa retórica circulante que explica la instrumentación de las políticas sociales inclusivas constituidas en lenguaje técnico e incluso en subjetivación. En el PIS existe incluso una justificación moral para su aplicación, en tanto "se trata de dar trabajo de forma tal, que se fomente la cultura del trabajo, ya que este es sinónimo de dignidad, confianza, capacidad de progreso, independencia y libertad" (Suárez Godoy, 2004, p. 38; cursivas añadidas). Desde este tipo de relaciones se apunta a modular la experiencia social, conforme a dispositivos y mecanismos institucionalizados que envuelven y moldean las prácticas, las formas del hacer y aprehender vivencias, los términos expresivos y las narraciones. La organización de las percepciones y significados, de las prácticas y expectativas, están relacionados así con los contenidos existentes y a la vez posibles que ponen en juego los dispositivos del poder, dando sitio a lo que los sujetos han de entender por inclusión.

Frente a este marco de sentido -que encuadra las prácticas en el tiempo/espacio, conforme a argumentos razonables, sensatos y convincentes- podemos contraponer una perspectiva fundada en la 
vida cotidiana que tensiona de manera particular los principios de la inclusión social y el punto de vista del derecho ciudadano. Resulta productivo recuperar aquí la obra de Raymond Williams (2000), para quien la experiencia asume una naturaleza activa que anuda de manera viva pasado y futuro en el aquí/ahora, otorgando un carácter excedentario y desbordante a la aparente totalidad cerrada de los mecanismos y dispositivos de la dominación. En sus trabajos de exploración de la lengua inglesa, el autor concluye dos sentidos generales sobre el término (Williams, 2003). El primero refiere a las lecciones provistas por el pasado, en tanto aprendizaje generalizable fundado en el experimento y la observación. El segundo acentúa la particular conciencia sobre el presente, que reúne tanto al pensamiento como al sentimiento (no solo a la razón y al conocimiento), conformando un estado o condición interna y personal. En este marco, Williams especifica que mientras la primera idea abarca ciertos aspectos de la segunda, no sucede a la inversa. La construcción de la experiencia en tanto pasado ya contiene la referencia a procesos reflexivos y de análisis del segundo tipo, lo cual no sucede en las nociones más extremas de experiencia presente, relativas a la inmediatez y la naturaleza incuestionable de los acotamientos.

En Walter Benjamin, por otra parte, el mismo término parece referir a una confluencia entre ambos sentidos, consolidando una imagen socio-histórica que da cuenta de la capacidad de apropiación socioindividual del vínculo entre el mundo y sí mismo. La experiencia puede ser interpretada desde aquí como un proceso activo que articula acontecer y acontecimientos en términos de las relaciones complejas entre pasado, presente y futuro. Este proceso, en definitiva, no deviene espontáneamente sino como praxis: condición del obrar autoconsciente de un sujeto que articula (y vuelve articulables) los aludidos elementos (Weber, 2005). La experiencia es entonces resultado de un ejercicio activo, reelaborado cada vez ante los acontecimientos como efectivo trabajo desde el hacer, el pensar y el sentir, por mediación del recuerdo/la memoria y la posibilidad de su comunicación, que implican tanto una dimensión socioindividual como una colectiva.

Si existe para nosotros cierta relevancia en estas concepciones, es precisamente porque colocan al sujeto como verbo del sentido del mundo y lo observan, en su envés, desde un punto de vista materia- 
lista ${ }^{3}$. El ejercicio de la praxis está vinculado al acontecer como acto de afirmación del sujeto que trasciende la simple elaboración de una imagen o lectura del mundo. Comprender las experiencias dentro de la dinámica del orden social que imponen las políticas sociales implica precisamente expresar la relación conflictiva entre las pretensiones de dominación y las situaciones concretas por las que atraviesan los sujetos. Es decir, habilita un continuo interpretativo que enlaza los componentes regulatorios, discursivos y prácticos ya mencionados. En este marco es que es posible recuperar la resignificación de los espacio-tiempos colectivos e individuales, evidenciando formas de pensamiento y sentimiento a contrapelo de lo instituido y tensiones y disputas frente al avasallamiento de los actores político-económicos dominantes y la hegemonía discursiva. Esta pugna está ligada a la reapropiación del sentido de la vida cotidiana, de los espacios y las relaciones, en tanto la reinterpretación del estar/hacer/sentir será abordada, en nuestro caso, desde las expresiones de los beneficiarios del Programa Concertación con la Comunidad/Plan de Inclusión Social.

Como parte de este marco analítico y a fin de sondear las experiencias, hemos privilegiado un diseño cualitativo que se orienta a la producción de conocimiento sustantivo (Valles, 1999) y que es pieza de una investigación mayor ${ }^{4}$. La interpretación del contexto situado, la historia y la estructura social resultan fundamentales en esta dirección, llevándonos a priorizar el acceso a la información por dos vías: desde el uso de fuentes secundarias, que incluye estadísticas, documentos oficiales y notas periodísticas que permiten explicitar las características de la política indagada y su inscripción en la dinámica social; y a partir de entrevistas semiestructuradas (algunas individuales, otras colectivas) que dan acceso a la expresión de los sujetos desde la palabra, organizada en particulares percepciones y emociones. Partiendo

3 En un trabajo anterior (Seveso, 2014) hemos expuesto de manera extensa los fundamentos de indagación de las políticas sociales desde la noción de experiencia, repasando las perspectivas hegemónicas de análisis sobre la desigualdad/la pobreza en América Latina en contraste con una perspectiva sociológica fundada en las nociones de historia, clases sociales y conflicto.

4 Para el artículo presente, la principal fuente de datos proviene de entrevistas realizadas entre el año 2007 y 2018 a los beneficiarios del SCC en la ciudad capital, trianguladas mediante conversaciones con técnicos de jefatura, registros sistemáticos de medios de comunicación y datos estadísticos. En los fragmentos de cita la cursiva corresponde a destacados del autor. 
de los registros que habilitan estas técnicas -y como resultado provisorio de la estrategia metodológica escogida- es que enfatizamos la importancia de contextualizar en un primer momento el fenómeno en estudio, interpretando en sucesivo la expresión situada de la palabra desde las correspondencias y tensiones del sentido emergente, según lo dicho y lo silenciado, lo visible y lo soterrado.

Como parte de este proceso, buscamos superar el punto ciego que deshistoriza, individualiza y elude el carácter conflictual de las relaciones sociales, sustentando una crítica a las estrategias de instrumentación política que son impuestas sobre las clases subalternas (Seveso, 2016). La indagación y visibilización de las experiencias, en este caso particular, permitirá problematizar, como ya hemos anticipado, la política de inclusión, poniendo en el centro la potencia de una sensibilidad cotidiana que revela las fuerzas activas del poder que atraviesan, subsumen y detienen a los cuerpos.

\section{Estar, hacer y sentir: marcas de las políticas sociales sobre la experiencia}

Las condiciones de desigualdad, desocupación y pobreza en Argentina solo pueden ser comprendidas a partir de los influjos del modelo de acumulación vigente, con un particular impacto en las diferentes regiones del país según las estrategias de desarrollo adoptadas. Hablamos de una historia de cuatro décadas que ha sido indagada localmente por diferentes analistas, teniendo como centro de discusión a las políticas neoliberales ${ }^{5}$. Conforme con ello, el modelo económico de la provincia de San Luis puede ser caracterizado actualmente por la prevalencia de un sistema agroindustrial, la principal fuente de bienes productivos y exportables. Una de las características de este sistema es la explotación intensiva de la tierra que, vía tecnificación y meca-

$5 \quad$ Ver, por ejemplo, los trabajos de Seveso (2015), Mario (2010), Azpiazu (1988) y Schvarzer (1987). Sobre todo cabe destacar las políticas de promoción industrial iniciadas a mediados de la década de los 70, que, por un lado, expandieron el parque empresario -mejorando las condiciones de empleabilidad y los salarios-, pero llevaron, por otro lado, a la radicación precaria de matrices instaladas en otros lugares del país y América Latina. Debido al bajo valor agregado en los productos y al moderado fomento de cadenas productivas, muchas empresas quebraron o desanclaron sus establecimientos cuando el escenario de expansión económica y los incentivos impositivos se vieron afectados hacia mediados de los 90, generando un fuerte impacto en las condiciones de empleo a nivel local. 
nización, reduce progresivamente los costos variables y minimiza el uso de la mano de obra. De hecho, la manufactura liviana ha contraído su participación en el proceso productivo local, siendo apuntalada por ciclos breves de recuperación que no alcanzan los niveles de décadas anteriores. En su lugar, el turismo y las industrias culturales ganaron sucesivo impulso para la generación de empleo, pero conformando puestos de baja calificación con escaso arraigo en cadenas productivas (Ministerio de Hacienda, 2018). Los efectos de esta dinámica se revelan en situación de desocupación que afectan a poblaciones crecientemente excedentarias y supernumerarias, convocando la intervención del Estado a través de iniciativas de protección social.

El marco de conflictividad que han abierto los procesos de desarrollo productivo, signados por condiciones de desigualdad y precariedad crecientes, es lo que da pie a la aplicación progresiva de planes asistenciales y programas condicionados. De acuerdo con los datos provistos por el Instituto Nacional de Estadísticas y Censos (INDEC), para el año 2003 las cifras de desempleo en la provincia de San Luis alcanzaban el 11,7\% y existía un nivel de subocupación demandante y no demandante del 16,5\%. Entretanto, el 54\% de los hogares se encontraba por debajo de la línea de pobreza y el $27,7 \%$ en situación de indigencia. Las trayectorias sinuosas entre la formalidad y la informalidad constituyen una constante dentro de este escenario, marcando las experiencias de los beneficiarios con los que tuvimos la oportunidad de entrevistarnos. Su memoria remite a los avatares entre la expansión y la recesión del mercado de trabajo, así como a la sucesiva institucionalización de los planes compensatorios que garantizan un acceso relativo a ingresos regulares, casi siempre primordiales y en ocasiones accesorios.

M: En el 2000 me dejaron sin trabajo a mí (...) todas las fábricas empezaron a dejar afuera a la gente (...) Después de eso yo, eh, me dieron una pasantía; con esa pasantía estuve... tres años ${ }^{6}$. (...) Una pasantía de $\$ 300$, una pasantía donde vos tenías que trabajar en política ¿Me entendés? Ahí empecé a trabajar en política yo. Ahí vos tenías que hacerle la política a ellos [al gobierno oficial] ¿Te acordás

6 Se refiere al "Plan Social Evita Para Todos", vigente hasta el proceso de "Reordenamiento, Transformación y Modernización del Estado Provincial" que sirvió de base a la implementación del PIS. 
que [antes] se entregaba la caja del PAN? (refiriendo al Programa Alimentario Nacional). La caja de mercadería esa que se daba, no sé si te acordás (...) A mí me tocaba eso, hasta que ganó el Alberto [Rodríguez Saa] y asumió el Alberto. Porque toda la política del Alberto se hacía: mañana le damos la copa de leche a los niños y a la tarde salimos a folletear, o sea, a entregar los votos casa por casa a la gente, todo eso ¿Entendés? Se hacía eso, después de caminar todos estos barrios puerta por puerta para entregar los papeles del Alberto (...) Después resultamos para el Alberto ser todos ñoquis [coloquialmente, quienes cobran sin trabajar], porque nunca trabajábamos (...). En El Diario [de La República] ${ }^{7}$ dice "todas estas personas que hasta el momento -no sé cómo decía en ese momento El Diario, los ñoquis, algo de ñoquis decía- esteee, van a pasar a parcela [al Plan de Inclusión Social] el que quiere, y el que no, se queda afuera, se queda sin trabajo" (...) Después de haberle hecho toda la política, bueno, ahí nos mandaron a parcela, ahí; ahí yo fui a la parcela, me presenté el día que me tenía que presentar en la parcela que esta allá al lado del río, y de ahí yo me pase a Seguridad Comunitaria. (Entrevista a Mónica, 15 de mayo de 2010).

En este fragmento, una beneficiaría narra desde el sitio del "yo" una trama temporal asociada a las dinámicas del mercado de trabajo, la política partidaria del gobierno y los instrumentos de la asistencia estatal. El principal punto de quiebre en su trayectoria es datado en proximidad al año 2000 como punto de inflexión en el empleo formal y tránsito hacia la precariedad en el contexto crítico nacional del año 2001, una crisis económica sin precedentes. Esa narración temporal va, sin embargo, hacia atrás y hacia adelante, atando cabos a partir de las modalidades sistemáticas de la asistencia estatal dentro de un entorno social crecientemente conflictivo. Así, el evento individual -extrapolable a otros casos indagados como suceso colectivo- marca un quiebre con las narrativas del trabajo tradicional y su capacidad apelativa universal, sustituida por prácticas de "rebusque", en primer término -particularmente fundadas en el autoempleo y la inserción informal-, con ciclos variables de contratación efectiva. Dentro de este contexto

7 Es el principal diario de circulación local, de línea oficialista y de propiedad de Alberto Rodríguez Saa, cuya familia mantiene la dirigencia del poder ejecutivo desde el retorno de la democracia en Argentina en el año 1983. 
es que adquiere sentido la compensación parcial del salario a través de estrategias de vinculación con el Estado, combinado la asistencia directa (como la caja del PAN) con la labor clientelar desde unidades básicas, hasta llegar a la inserción en programas condicionados.

El tránsito frenético que describe la entrevistada entre la actividad fabril, la práctica territorial del ser un puntero político y el "pase" forzoso a la asistencia con contrapartida implican, como parte de este escenario, una suerte de carrera del menoscabo personal a lo largo de casi dos décadas, que fue imponiendo salidas cada vez más limitadas frente al escenario masivo de desocupación.

En esta dirección, ante la situación de desempleo generalizado y la informalidad institucionalizada (vía programas de liberación económica, privatización de servicios públicos y flexibilización laboral), los planes sociales ocuparon progresivamente un lugar central como recurso de vida, constituyendo una demanda colectiva y un piso de las expectativas para el consumo en Argentina ${ }^{8}$. De allí que el plan de inclusión significara, localmente para gran parte de la población, más que una ayuda en tanto apertura a un camino (según señalaba nuestra entrevistada) para no quedar afuera y sin trabajo.

Sin llegar a comportar una política universal, el Plan de Inclusión Social adquirió un alcance masivo durante los principales periodos de crisis socioeconómica, incluso cuando los recursos destinados y el número de beneficiarios variaron con el tiempo. Un $25 \%$ del presupuesto aprobado para el año 2004 fue destinado a su ejecución, previendo 45.000 beneficiarios directos y la inclusión de 500 coordinadores generales, esto es, un cuarto de la población para entonces ocupada en la provincia (Suárez Godoy, 2004). Por su parte, el informe de gastos presentado por el ejecutivo para el año 2018 indicó que el 80\% de los recursos destinados al Ministerio de Desarrollo Social tenían por objeto al Plan de Inclusión Social y al Subprograma Concertación con la Comunidad, con montos acumulados de $\$ 520.105 .182$ y una cobertura de más de 31.000 beneficiarios (Gobierno de la Provincia de San Luis, 2018).

8 Para algunos ejemplos sobre este punto ver Zibechi (2010), quien destaca la lucha de los movimientos de desocupados por acceder a recursos económicos vía planes sociales. 
Así, en virtud de su alcance territorial, su nivel de cobertura en población y su extensión temporal, el Plan de Inclusión Social puede ser entendido como el pilar de las protecciones sociales de San Luis, desde su ejecución inicial en el año 2003 hasta la actualidad. Esto adquiere particular relevancia si consideramos que se trata de una política que durante mucho tiempo estuvo bajo la órbita de iniciativas subnacionales, con diseños y modalidades de ejecución propias en directa competencia con los principales proyectos nacionales, especialmente aquellos focalizados en el mercado de trabajo9 .

$\mathrm{N}$ : Acá tenes todos los niveles sociales, entendés. Acá como podés tener una persona que está a punto de recibirse, de tener un título, como hay gente pobre que no sabe ni leer ni escribir. O sea, el Alberto [gobernador] les ha dado la posibilidad a todos, entendés; a los chicos discapacitados, a todos. Eso es lo bueno, el Alberto no ha discriminado a nadie [destaca], a nadie (...).

B: Que es el que te ha dado la posibilidad.

$\mathrm{N}$ :...el que me ha dado la posibilidad de vivir dignamente, porque ser madre sola, darle de comer a tu hija, tener una casa a cargo, no es fácil, entendés. Y al menos lo podés hacer dignamente. No que te va a sobrar, pero podés decir: tengo a mi hija enferma, la llevo al médico, puedo comprarle los pañales, la leche (entrevista a Nira y Bety, 16 de mayo de 2007).

M: ¡Imagínate si no estuviera el plan, toda la gente que estuviera acá! Han venido de otras provincias también, de Córdoba, de Men-

9 Hasta el año 2019 la mayor parte de los planes de asistencia local eran considerados incompatibles con los de orden nacional. Esta situación cambió con el actual gobierno de Alberto Fernandez, que alineó su gestión política con los intereses provinciales. De acuerdo con Longou Díaz y Forteza, el Programa Jóvenes y el programa de Ingreso Social con Trabajo "Argentina Trabaja", de alcance nacional, no era implementados en San Luis por razones de voluntad política. "Efectivamente, el nivel de mortandad de los proyectos es de aproximadamente 90\%" (Longou Díaz \& Forteza, 2011, p. 40). Del mismo modo, el programa Ingreso Social con Trabajo no encontraba instrumentación, "puesto que las prestaciones del PRIS entrarían en competencia con el Plan de Inclusión Social de la Provincia" (Longou Díaz \& Forteza, 2011, p. 42). Se daba una situación similar con el programa Jóvenes con Más y Mejor Trabajo que no encontraba un acuerdo marco entre la nación y el gobierno provincial. Finalmente, las autoras señalan que la Asignación Universal por Hijo poseía escasa penetración en el territorio, hasta el punto de que San Luis es la única provincia que no firmó -hasta el año 2019- "el acuerdo de cooperación entre la ANSES y los gobiernos provinciales para la rápida implementación de la AUH" (Longou Díaz \& Forteza, 2011, p. 44). 
doza han venido, mucha gente, pero la mayoría de la que está ahora es la que vino hace 20 años, cuando vino la promoción industrial, yo por ejemplo.

Ho: Yo también.

M: Por la promoción industrial, y se terminó eso y después ya... (Entrevista a Mónica y Holga, 25 de mayo de 2009).

Frente a la fuerza expulsiva del mercado laboral, el brazo asistencial del gobierno significó para muchas personas la garantía de un ingreso regular, resultando en un mecanismo de sutura entre las necesidades vitales y los deseos. Por ello es interesante observar que el plan de inclusión es interpretado personalmente como un mecanismo legítimo, hasta necesario incluso por su impacto en las condiciones vitales. Así, "la posibilidad de vivir dignamente", otorgada "a todos" sin discriminación, aparece como una respuesta gubernamental aceptable. Por otra parte, la regulación activa del dispositivo evidencia un efecto desbordante, que devora y hace funcionales a los sujetos, produciendo sensaciones de malestar y padecimiento. El vínculo entre la política gubernamental y los intereses del mercado convocan a los beneficiarios desde su doble papel de trabajadores precarizados y consumidores activos, evidenciando una mecánica de mercantilización progresiva que a continuación vamos a puntualizar.

\section{El cuerpo (y sus energías) como capital}

Una primera dimensión puede ser recuperada en función de las energías corporales (tanto físicas como psíquicas y emocionales) que los beneficiarios del subprograma Concertación con la Comunidad ponen en juego mediante sus actividades de contraprestación ${ }^{10}$. En particular, según la dirigencia gubernamental, deben responder al apelativo de

10 Desde el punto de vista asumido en este trabajo, el cuerpo constituye la presencia primordial de los sujetos ante el mundo según su relación intrínseca con componentes biológicos, subjetivos y sociales, articulados por las fuerzas estructurantes/estructuradas del espacio social. En el primer sentido, el cuerpo es el sitio primordial de la reproducción energética: sin su formación y actualización, no existe presencia posible. Pero, a la vez, es el territorio a partir del cual todo sujeto configura su existencia como yo en el acontecer por el que "pasan" los procesos de estructuración. Finalmente, en su formación dialéctica, la apreciación y clasificación de los fenómenos se conforma (al menos en parte) de acuerdo con la posición y capacidad de disposición del sujeto en tanto cuerpo, en términos del espacio social estructurado y estructurante (Seveso, 2015). 
ser los "ojos y oídos del barrio" (Gobierno de la Provincia de San Luis, 2005), cuya tarea específica es la de brindar seguridad "a los vecinos del barrio y su patrimonio reportando actividades sospechosas, delictivas o potencialmente peligrosas" (Gobierno de la Provincia de San Luis, 2004, p. 2).

N: Yo me levanto a las 4 de la mañana, son las 5:30 y ya estoy acá para tomar el turno. ¿Entendés? Entonces yo, que me digan a mi "a vos el Alberto (el gobernador) te va a dar la plata porque sí"... yo vengo, cumplo (...) o sea, no me paga para quedarme sentada en mi casa, y como a ellos tampoco. Ellos (refiriéndose a otros protectores presentes durante la conversación) vienen y tienen que estar. Bueno, a ellos les ha tocado este lugar, de estar en un edificio público, pero tienen que estar (...) y es una responsabilidad muy grande. No podes tocar nada... estas acá y... se rompe, se pierde algo. (Entrevista a Nira, 2 de julio de 2007).

G: Vos decís “¿qué hace en la escuela esta?”. Bueno, cuidas, yo viste... he estado sola, hay PC (computadoras), tenés que cuidar las luces, que no se roben la cantera, que no apedreen en la escuela, muchas cosas. Como es decir, dejarla sola, no podes dejarla sola a la escuela. (Entrevista a Gustavo, 29 de noviembre de 2010).

En las actividades descritas, un rasgo fundamental que se destaca es la disponibilidad de los cuerpos en servicio para otros. Durante la etapa de mayor auge del subprograma (año 2006), fueron más de 7.200 agentes en todo el territorio provincial, de los cuales 4.000 estuvieron asentados en la ciudad capital. Este número luego se redujo significativamente hasta estabilizarse en unos 2.200 agentes en 2018, pero que mantuvo su marco de acción territorial segmentado y selectivo. Aún con escaso o incluso nulo nivel de profesionalización, los concertadores del SCC han sido orientados para la mediación de conflictos como principal brazo de innovación de la política de seguridad local, protegiendo el patrimonio y detectando situaciones potencialmente peligrosas. A través de sus acciones, la política de seguridad logró activar múltiples sentidos vigías (ojos, oídos, tacto) en los centros urbanos, en los barrios y en las edificaciones públicas como parte de una estrategia de accionar multidimensional contra el delito, en proximidad física y constante (Seveso, 2018). 
Esta modalidad de protección combinó dos formatos generales, con variación en: los recursos humanos disponibles, los diagnósticos de conflictividad urbana y la perspectiva de actuación de los agentes en el tiempo. Una de ellas estuvo enfocada en los barrios populares, sobre todo en la zona sur, y la otra en el área céntrica de la ciudad, la cual concentra la actividad comercial y financiera. Este proceso de oscilación derivó en momentos de ausencia de los protectores en ciertas zonas, confirmando la importancia que revestía el subprograma como garantía de vigilancia para algunos vecinos.

M: La gente me comentaba anoche, las chicas (refiriéndose a otras protectoras), que hay un señor de la manzana 10 que ha dicho "que no, que él va a pasar una nota, que no puede ser, que levanten la seguridad (en el barrio), que era muy importante", que a ellos les cubrían la casa, que por lo menos ellos podían salir tranquilos, porque sabía que había alguien dando vuelta o que algo iban a ver. (Entrevista a Mónica, 4 de abril de 2010).

M: Por donde está el negocio de la Lily que yo te digo, ella me dijo "oh, se fueron, y no hay turno a la noche de dieciocho a veinticuatro en ese horario que se ponen a tomar cerveza acá en la puerta del negocio". Una vez le quisieron robar; me dice "¿Por qué no los vemos más acá en el barrio?", "no -le digo- por lo que los sacaron" (...) firmaron los vecinos para que nos dejaran viste, pero no, ya la orden te venía de allá (de la jefatura), viste. (Entrevista a Mónica, 15 de mayo de 2010).

Si en esta cita hay una referencia directa a los efectos de la acción, una investigación previa evidenció que, efectivamente, gran parte de los vecinos de la ciudad -y en particular aquellos pertenecientes a los sectores medios- han sostenido a lo largo del tiempo una visión positiva sobre las tareas de protección. El procesamiento de la encuesta realizada por la cátedra de Psicología Jurídica de la Universidad Nacional de San Luis (año 2004) permite afirmar que el 46\% de los vecinos del centro capitalino tenían una opinión entre buena y muy buena durante las primeras fases de ejecución de la política. Así, el 22,3\% del total manifestó sentirse más seguro desde su implementación y el $16,5 \%$ consideraba que percibían una reducción del delito en la ciudad (Seveso, 2015: p. 246 y ss). De hecho, durante algún tiempo los concertadores constituyeron una fuerza de acción subsidiaria a la 
policía, apoyando operativos de seguridad y participando en procesos de allanamiento ${ }^{11}$. Mientras tanto, los focos de interés productivo y las áreas "calientes" del delito fueron estructurando estratégicamente el recorrido concentrado y/o dilatado de los cuerpos-vigía y su formato de acción. Sobre todo, la asignación concentrada de los Protectores en el centro de la ciudad estuvo relacionada inicialmente con el propósito de la vigilancia y protección de bienes y servicios en las principales zonas comerciales y financieras. Este direccionamiento puede ser asociado igualmente a la construcción de una imagen deseable de la ciudad, afirmada en espacios seguros/asegurados para el turismo ${ }^{12}$.

Este mismo uso estratégico y variable llevó a que los protectores fueran sometidos a movimientos oscilatorios no solo entre espacios, sino además entre tareas: sirviendo como cordones de seguridad en establecimientos educativos, vigilando paradas de transporte y estaciones de autobús, así como colaborando en eventos deportivos y festividades. Desde este lugar, el eslabón que conecta la política de inclusión con la protección ciudadana -en una urbe de escala media en continuo crecimiento- dependió funcionalmente de la disponibilidad de los cuerpos para la ejecución de actividades específicas. Es por esto que, aun cuando el subprograma ha sido cuestionado por su escaso impacto en el delito e incluso constituya un foco de juicio colectivo, su modalidad de acción señala condiciones de expropiación de energías

11 Sobre este punto, una beneficiaria aclara:

Agarraban de la zona a... a Seguridad Comunitaria, a dos personas o tres. Las llevaban al lugar del allanamiento, y vos tenías que ir y a dar la cara (...) nosotros colaborábamos, a contar las cosas, a ver qué es lo que había, a anotar...y todo eso como si fuéramos policías (...) Si mataron a alguien en una casa, también nos llevaban (...) Después para buscar las balas, para ayudar a buscar entre medio los yuyos, las balas, todo eso. (Entrevista a Gladys, 27 de mayo de 2016).

12 La terminal de ómnibus y el centro de la ciudad fueron resaltados reiteradamente como focos de intervención. El periódico oficial especificaba entonces: "se busca que Seguridad Comunitaria y la Policía trabajen en forma conjunta en la terminal. Los protectores van a tener una base en el destacamento y patrullarán con los policías. Si la experiencia da resultado, se ampliará a otros puntos de la provincia" (...) El jefe del Programa Mario Vera Aráoz señaló: "La idea es disminuir todas las posibilidades de delito y favorecer el turismo, que las personas que pasen por esta terminal y no sean de San Luis se lleven la verdadera imagen de San Luis (...) La terminal, además de ser la cara de la ciudad ante el turista que llega, es una zona de conflicto y riesgo permanente" (El Diario de La República, 2008). 
sociales con efectos propiamente productivos, especialmente cuando son considerados en su escala global ${ }^{13}$.

Solo para dar un ejemplo vinculado con la rearticulación productiva de la provincia, es posible referir a las cinco celebraciones consecutivas del Carnaval de Río en San Luis realizadas entre los años 2010 y 2015. Este evento, año a año reunió a scolas de Río de Janeiro (Brasil) con cientos de pasistas (bailarines y bailarinas) locales en uno de los principales destinos turísticos provinciales: Potrero de los Funes. Marcando las tendencias del progreso en la ciudad, el evento fue reconocido como un ícono de la inclusión y destacado por su capacidad para "potenciar y ubicar a la provincia en los primeros lugares del turismo nacional e internacional” (Agencia de Noticias San Luis, 2014, párr. 4). Para ello, contó con la contribución específica del programa: "150 beneficiarios del Plan de Inclusión Social confeccionaron los 1100 trajes alegóricos que desfilaron" Agencia de Noticias San Luis, 2014, párr. 31 ), mientras la presencia activa de los protectores garantizó los cordones de vigilancia y la protección al turismo, tanto en la zona de las sierras como en las áreas centrales de la urbe (Agencia de Noticias San Luis, 2013).

Sobre la convergencia entre el subprograma y las políticas productivas locales, finalmente, es importante señalar que de manera incipiente, en el año 2007, se inició una torsión estratégica en el SCC -"un nuevo camino del Plan" - que instituyó a las cooperativas de trabajo como mecanismos de organización colectiva. Apelando a la futura independencia de los beneficiarios, desde el horizonte de "un trabajo mejor con autonomía y determinación” (Guinard, 2013, p. 93), entre los años 2011 y 2015 el entonces gobernador Alberto Poggi -que sucedió como pieza de enroque a Alberto Rodríguez Saa durante una gestión- pro-

13 Para el año 2010, se estimaba que en el país existían 850 empresas de seguridad privada que facturaban en conjunto unos \$1.830 millones anuales. Sólo la Cámara Argentina de Empresas de Seguridad e Investigación (CAESI) amparaba a un total de 189 empresas/miembro, informando la existencia de unos 150.000 trabajadores formales, con una cifra en "negro" del $40 \%$ que llevaba los números reales a 250.000 empleados en el sector. "En el último acuerdo, firmado en abril, se propuso un aumento del 30,4\%, que se termina de integrar este mes y deja el sueldo en \$2400, para la categoría más baja" (La Nación, 2010, párr. 23). En comparación con estos valores, los Protectores del Subprograma de Concertación con la Comunidad percibían un salario de compensación de entre $\$ 600$ y $\$ 700$. La diferencia total supera el triple salarial, lo cual supone una forma potencial de ahorro en los gastos destinados a la vigilancia pública. 
fundizó este proyecto con epicentro en el sector privado, multiplicando los talleres del denominado Plan de Cooperativas Sueños y Progreso. Los proyectos fueron solventados por el gobierno, quien además de impulsar la capacitación, proveer herramientas de trabajo y asesorar en prácticas legales y administrativas, realizó la contratación directa de algunos equipos. Este fue el caso de Visión Cooperativa, integrada inicialmente por beneficiarios del SCC y contratada para brindar vigilancia electrónica en el Faro de la Sabiduría: una torre de $540 \mathrm{~m}^{2}$ que recibía imágenes de la red de cámaras digitales desde diferentes puntos del territorio. Las pantallas, divididas en cuadrantes, dependían de la actividad permanente de los agentes, quienes registraban los movimientos bajo la coordinación de un policía de las fuerzas especiales. El diario oficial supo destacar que el sistema "todo lo controla"; "[o]jos y más ojos, concentración absoluta a los movimientos que se observan en las calles puntanas"; "hay que ver, intuir, sospechar, comprobar y asegurarse"; "son 24 horas los 365 días del año" (El Diario de La República, 2011, párr. 20-38).

G: Cada cámara tiene su operador. Entonces si ese operador no fue, esas cámaras que quedan ahí sin operador, es repartido por el resto. Entonces si yo tenía 14, capaz que tengo 16 o 18 cámaras, para mirar (...) son 2 monitores que yo tengo enfrente mío (...) Yo imagínate, yo me he memorizado qué cámaras tengo ahí, qué calles son, donde están las cámaras. Entonces, si yo escucho la radio que pasó [refiriéndose a la frecuencia policial] (...) yo ahí inmediatamente "ah, la tengo yo"; ahí nomás busco y tengo que ver (...) y enfocarlo, grabarlo y todo eso. Porque eso queda grabado. (Entrevista a Gladys, 27 de mayo de 2016).

Si en general las actividades de los programas condicionados apuntan a sectores intensivos -incluyendo servicios a la comunidad, tareas de limpieza y parquizado, construcción y mantenimiento de infraestructura-, en este caso observamos un despliegue profundamente técnico que descansa en la formación práctica (aunque no profesionalizada) de los agentes. Aun en condiciones del trabajo cooperativo "intramuros" -que elude la fuerte exposición ambiental que implicaba la vigilancia en las calles-, todavía se relatan situaciones de padecimiento constante: dolencias de vista y de cabeza por la presencia forzada y permanente en las pantallas debido a los descansos breves y 
espaciados. A ello se suman molestias en las manos, en la espalda y en el cuello por la posición tensa del cuerpo; y situaciones de frio y calor (afectadas por goteras en las áreas de vigilancia) asociadas a un espacio deficitario de trabajo.

G: Te imaginás si hace 5 años que yo estoy ahí con las cámaras, este... ya tengo la columna hecha bolsa, digamos; la columna, las cervicales, la vista, la cabeza, todo (...) llega la noche y yo me quiero acostar. No quiero nada. No quiero salir, no quiero nada. No quiero música, no quiero nada. Imaginate, tenemos la... las dos pantallas, más aparte de las dos pantallas tenés la radio policial que está permanentemente hablando. Y fuerte; porque todos tienen que escuchar y vos tenés que estar pendiente de lo que la radio dice. (Entrevista a Gladys, 27 de mayo de 2016).

El dolor físico es, entonces, una marca asociada a las tareas y al que se le añade el cansancio que aploma la acción hacia el final de la jornada. Ante ello, el reposo y el sueño aparecen en la cita anterior como única acción capaz de restituir las energías puestas en ejercicio, cuando cinco veces es señalada la expropiación del deseo como negación: no querer más nada.

En relación con los procesos de cooperación, el entonces ministro de inclusión social supo expresar que se trataba de "una oportunidad extraordinaria" que animaba "a soñar y a tener una proyección en el futuro" (Guinard, 2013, p. 160). Lo cierto es que, de a poco andar, muchos equipos fueron disueltos, ya sea por inconvenientes en la coordinación colectiva, el inadecuado uso de los fondos o la falta de renovación de los contratos. En el caso de Visión Cooperativa, se produjeron numerosas deudas impositivas ante un desfalco financiero y posteriores solicitudes de embargo. A nuestro entender, más allá de este evento crítico, la torsión estratégica hacia la configuración de las cooperativas modificó los compromisos hasta entonces asumidos por el gobierno local, restituyendo la soberanía del mercado como mecanismo de regulación. La dislocación progresiva de los sujetos respecto al plan, como reverso de la retórica de movilidad social y autodeterminación promovida, ocluyó así la tendencia centrífuga hacia el desamparo. Por otra parte, es importante ponderar aquí la directa relación entre esta fase de cooperativización y la segmentación creciente de la cuadrícula urbana para su custodia. Como parte de las acciones de mapeo policial, el sistema 
de vigilancia panóptico de la ciudad se desplegó inicialmente gracias a la capitalización directa del trabajo individual de los protectores y del colectivo de cooperativistas en condiciones de profunda precariedad. Las cámaras fueron utilizadas como instrumentos disuasorios y preventivos -e incluso como prueba ante la justicia- y permitieron la visualización de amenazas potenciales o efectivas en tiempo real. Desde la circulación en las calles y la permanencia en espacios de clausura hacia el control vigía, potenciado por los instrumentos digitales, las energías de los beneficiarios fueron puestas una y otra vez al servicio de la seguridad en su conjunto, teniendo al cuerpo como principal activo de realización.

\section{Mercantilización cotidiana desde el consumo}

Las referencias del apartado anterior nos recuerdan que el contraluz de la inclusión al mercado de trabajo es la expropiación de las energías disponibles en los sujetos. Esto implica condiciones profundas (pero a la vez porosas) de capitalización en parte válidas para la política indagada porque integra en su diseño formas efectivas de contraprestación. Según veíamos, esto deriva en consecuencias prácticas para los beneficiarios, traducidas en una cobertura mínima de necesidad, pero también en inseguridades y padecimientos cotidianos. El diseño de los programas pondera la contribución directa de cada individuo a dinámicas productivas como corresponsable de procesos o servicios productivos, pero dentro de un marco de desprotección social generalizado que está anclado a la mercantilización del cuerpo.

Un segundo camino por el que se expresa el vínculo entre la inclusión social y la dinámica mercantil es el incentivo a la compra de bienes y servicios. Desde un imperativo procedimental y praxiológico que fetichiza los objetos, nuestras sociedades imponen un dictum superlativo para la formación del yo desde el fundamento del consumo como bienestar personal. Considerando este punto de vista, ciertamente que el mercado interpela a los beneficiarios de las políticas asistenciales como consumidores, pero esta lógica social también forma parte del diseño vertebral del programa analizado. En términos de los impactos esperados por el gobierno provincial, la implementación del PIS debía constituir desde sus inicios "un estimulante clave para el crecimiento 
de la actividad comercial en la Provincia" (El Diario de la República, 2003, párr. 6). Así, a pocos meses de ser ejecutado, el periódico oficialista realizó una encuesta comercial que ponderaba sus beneficios relativos. Los datos señalaban que el dinero inyectado a la plaza local era de unos $\$ 4,5$ millones mensuales, partiendo de la base de una remuneración de $\$ 300$ por persona, de los cuales el $70 \%$ era destinado a bienes comestibles y artículos de primera necesidad, seguido por la vestimenta y otros insumos. "Las ventas crecieron entre los bimestres abril-mayo contra junio-julio más del 7\%”, afirmaba el periódico; los supermercadistas aseguraron que de ese promedio, el $2 \%$ estuvo influenciado directamente por las compras pagadas con cheques de inclusión social, que es el instrumento a través del cual se cancelan los haberes de los trabajadores del plan de empleo (El Diario de la República, 2003, párr. 19).

Como figura representativa de la relación entre política y economía, en general, y entre el plan social y la dinámica de consumo, se repetía la figura del círculo virtuoso ya presente en la ley general del PIS: "A más de tres meses del funcionamiento del plan de inclusión, ese círculo ha comenzado cerrarse y ya hay signos evidentes de recuperación en sectores como el comercial" (El Diario de la República, 2003, párr. 15). Parte de esta dinámica fue promovida directamente por el gobierno provincial a través de los denominados cheques de inclusión: la moneda corriente (y diferencial) designada para el intercambio en forma de pago salarial y habilitada para la compra directa. De hecho, los comercios locales contaban con beneficios especiales para su uso, además que podía ser intercambiable por dinero corriente.

Yo lo veo en el centro -nos decía uno de los beneficiarios- (...) pero el que es vivo es el Aiello para mí [el propietario de la mayor cadena de supermercados locales]. Recibe y te da un peso; tenés que gastarle todo ahí ¿Me entendés? (Entrevista a Gustavo, 7 de enero de 2011).

En este punto, la cadena de circulación establecida entre el gobierno provincial, los comercios y el sistema financiero fue dando forma a circuitos de capitalización, pero estableciendo marcos diferenciales de beneficio según clases. La moneda vuelta rasgo singular de la política expresa de hecho la consumación del poder para ciertos sectores eco- 
nómicos y políticos, así como la regulación activa y la dependencia de los sectores subalternos que cayeron bajo la órbita de la asistencia ${ }^{14}$.

Esto reaparece bajo una forma diferente en la liberación de créditos para la compra de bienes, a través de alianzas estratégicas entre la gestión gubernamental y ciertos sectores empresariales. A partir del año 2003, el gobierno provincial ejecutó diversas iniciativas para el acceso a tecnologías de la información, como computadoras portátiles, tabletas electrónicas y antenas de wifi. Estas decisiones fueron diferencialmente orientadas según tipologías de destinatarios, por un lado, entre niños, docentes y jubilados, y por otro, familias de escasos recursos y sectores medios. Según expresa la siguiente cita, referente a la compra de un dispositivo electrónico de escritorio, este tipo de iniciativas inclusivas tuvo consecuencias negativas para las economías domésticas.

M: (...) con $\$ 600$ [el salario mensual recibido para entonces] ¿Qué hacés? No hacés nada, encima la mayoría de las personas no cobran los $\$ 600$; todos cobran 400,430 , porque nos metieron la computadora esa (...) El gobierno abrió un plan de computadoras el año pasado, el anteaño pasado, cosa que cada uno podía comprar la computadora que quisieras ¿Entendés? Y la mayoría se metió.

G: Compró.

M: Se metió en computadoras, entonces no cobrás nunca los $\$ 600$ porque viene ya descontada la computadora. (Entrevista a Mónica y Graciela, 4 de abril de 2010).

La referencia dada por Mónica y Graciela señala el acceso vía crédito que el gobierno provincial facilitó para los beneficiarios: una iniciativa de consumo fundada en el endeudamiento directo y atada al ingreso provisto por el plan de inclusión. Por esta vía, el círculo virtuoso del consumo se cierra desde la captura del salario. Esto está directamente vinculado con la concepción de ciudadanía formal que actualmente expresa la Constitución provincial, formalizada en un nexo entre el

14 En esta dirección, una coordinadora del SCC nos decía: “Todo esto es político. Esto arranca por política (...) Entonces la gente tiene un trabajo y son cheques que permiten ciertos negocios. Es como en la época qué se yo, de antes, feudal ¿Me entendés? Son como esclavos" (entrevista a Liliana, 15 de mayo de 2007). 
derecho a la inclusión social y el derecho a la inclusión digital ${ }^{15}$. En ello opera una matriz de necesidades y expectativas que moldea las formas de lo deseado/deseable como lógica de inclusión social desde el mercado, en un sentido similar al que Zygmunt Bauman (2007) especifica como estructura moral de las actuales sociedades líquidas. Desde este punto podemos desplazar la interpretación de la política estudiada desde la acción productiva de los beneficiarios (asociada a la protección de bienes que apela a la entrega del cuerpo, referenciada incluso en computadoras que deben ser cuidadas en las escuelas, según marcaba una de las primeras citas) hacia la apropiación productiva de objetos codiciados como mercancía personal.

Retomando las referencias en la cita anterior, es significativo señalar que, en tanto consumidores, los beneficiarios permanecen atados de manera contractual al mercado, asumiendo por medio del crédito el compromiso de compra y el descuento a su salario. Mientras tanto, como trabajadores del subprograma su relación salarial es no contractual, ya que el Estado puede desarticular sus beneficios en cualquier momento. En función de esta diferencia, pareciera que son los objetos (y no los sujetos) los que adquieren verdadera centralidad como parte de la política de inclusión, anclados a procesos de producción y de consumo cuya fe perceptual (Benjamin, 1985) sostiene la creencia en el mercado. En esta torsión, la importancia de pertenecer al mundo de las mercancías en estados de precariedad no habla, como podría señalarse valorativamente, sobre la naturaleza insensata del beneficiario consumidor, sino de los mecanismos que lo interpelan de manera subrepticia. Desde los bordes del trabajo hacia la centralidad del consumo, la sensación de inclusión vuelve soportable los malestares sustentados por el deseo de una vida indigna. Al menos, en parte, esta es la razón por la que Mónica refiere ambiguamente a las consecuencias del acto de consumo. La adquisición de mercancías construye y recons-

15 Dice la Ley No XIII-0755-2011:

Enmiéndese la Constitución Provincial, incorporándose el Artículo 11 Bis, el que una vez culminado el procedimiento previsto por el Artículo 287 de la misma, quedará redactado como texto Constitucional de la siguiente manera: Artículo 11 Bis.- Esta Constitución reconoce todos los derechos y garantías establecidos en la Constitución Nacional, a los que considera un piso, por sobre el cual la Provincia de San Luis puede establecer mayores derechos y garantías. Todos los habitantes de la Provincia, gozan de los Derechos de Inclusión Social y de Inclusión Digital como Nuevos Derechos Humanos fundamentales (Gobierno de la provincia de San Luis, 2011, p. 1). 
truye el yo a partir de una dinámica expropiatoria que encuentra en la regulación del deseo un anclaje fundamental de reproducción. Entre tanto, las deudas contraídas son el punto de entrega (el sacrificio) que configura, a la vez, la sensación de conquista y bienestar personal, pero también de pérdida y de falta. La práctica sacrificial del sujeto demanda ese imperativo ritual, cotidiano, de creencia y entrega, fundado en la deuda permanente.

G: (...) ¡No sabes lo que nosotras hemos pasado! Pero yo lo amo a este trabajo, porque gracias al Alberto [al gobernador] yo pude comprarle zapatillas a mis hijos. No sabían lo que eran zapatillas nuevas. Así que si yo tengo que dar la vida por el trabajo, por el Alberto, la doy ¡Yo qué! Fijate que yo tenía... y tengo "mi casa" [destaca] en Mendoza [una provincia limítrofe], y tuve que abandonar mi casa en Mendoza porque en Mendoza jamás me ayudaron, jamás. (Entrevista a Graciela, 16 de mayo de 2007).

Como fieles creyentes en la religión laica del capitalismo, los beneficiarios del Plan de Inclusión Social están sometidos al imperativo de la mercancía convocante desde los mercados de la producción y del consumo que afirman su lugar en el mundo. Como mano de obra barata, flexible y precaria, inserta entre los pliegues inadvertidos de la explotación, son interpelados y expoliados desde la condición del hacer para tener. Esto implica más que un reconocimiento sobre el valor de las cosas, nos habla del pleno convencimiento de entrega hacia ellas. Ser interpelado por un sentido profundo que desborda al yo, unido a la marca que invoca la fantasía del consumo, es precisamente uno de los rasgos que revela la operatoria de la estructura de experiencia en nuestras sociedades; un llamado a la práctica sacrificial que, en este caso, convoca al Estado como representante de intereses asociados a la dinámica del mercado. "El amor por el trabajo" y "la vida por un objeto" son expresiones que ligan el compromiso directo del sujeto con el acto del consumo y, así, con los medios que lo garantizan: el trabajo precario y la política social. Como bien decía una de nuestras entrevistadas, el vínculo donante-receptor es el que estructura el sentido del juego como parte del diseño del programa; por eso "yo lo voto al Alberto [al gobernador], porque gracias a él tengo este trabajo" (entrevista a Leticia, 15 de mayo de 2010). 


\section{Conclusiones}

Dentro de la esfera pública, las políticas de inclusión al mundo del trabajo son legitimadas por su pretendida ampliación de derechos sociales para los sectores vulnerables. En su consecución práctica, sin embargo, estas invisibilizan la larga historia de desmaterialización, individualización y fragmentación que ha sufrido el empleo en Latinoamérica, así como la desarticulación de la lucha de los colectivos trabajadores que llegó a cristalizar en políticas desarrollistas hasta entrada la década de los 70.

Según hemos evidenciado en este trabajo, la ingeniería renovada de las políticas sociales es generalmente considerada virtuosa, pero no exactamente por las razones que esgrime su escenificación. El paso de la asistencia focalizada y restrictiva hacia programas de cobertura generalizados logra suturar las condiciones conflictuales producidas por el capitalismo en su versión neoliberal. Esto supone una respuesta técnica en condiciones de crisis del capitalismo, que contribuye activamente -desde la figura renovada de un Estado progresista y sus políticas de segunda generación- a un círculo virtuoso entre expulsión social, mercado de trabajo y dinámicas de consumo. En particular, hemos observado que la sinergia activa con el mercado no solo brinda una respuesta al problema de la desocupación desde abajo, sino también a los costos sociales posibles hacia arriba.

La heterogeneidad actual en el mundo del trabajo implica condiciones ocupacionales muy diversas, con regulaciones limitadas en los segmentos inferiores y un impacto indirecto en los procesos de crecimiento. En relación con ello, hemos argumentado que una de las consecuencias de las políticas de empleo condicional y transitorio es ampliar, sobre esta esfera, la existencia de un derecho "a la baja”, volviendo equivalentes procesos de trabajo diametralmente disímiles que parten de la base socialmente común que caracteriza a la población desocupada y en situación de pobreza. Esto constituye una argucia doblemente técnica y retórica, en condiciones en las que el modelo económico de América Latina revela una estructura de desigualdad fuertemente polarizada y fragmentada, signada por el crecimiento sistemático de la desigualdad. Así es que desde abajo la política estudiada favorece la circulación comercial/financiera mediante la doble figura de trabajadores activos, que son encarnados en cuerpos de seguridad, 
y de consumidores sagaces, afincados en la dinámica mercantil socialmente promovida.

Concretamente, el salario pagado se constituye en un medio de acumulación general, en tanto instrumento que dinamiza la producción, la circulación y el consumo de bienes y servicios, complementando la actividad regular de los beneficiarios que refuerza las condiciones de seguridad en la trama urbana. Esto constituye una comunidad de interesados, no solo entre el mercado, el Estado y la sociedad civil, sino también entre los mismos beneficiarios que son objeto de esta intervención. Por ello, la situación de dependencia del salario se instituye como una condición que los sujetos soportan desde el cuerpo y valoran expresivamente. La voluntad de estar en servicio vuelve perceptible la naturaleza horrorosa del no tener en un mundo organizado por un inmenso arsenal de mercancías que convoca de manera constante a los sujetos y se impone sobre ellos; en este caso, nada menos que desde la figura del productor-consumidor inscrito en un espacio político de reconocimiento de derechos.

En segundo lugar, puesto que este tipo de mecanismos satisfacen la deuda de los derechos de ciudadanía -respondiendo simultáneamente a la gestión de la sociedad civil y del mercado-, observamos que constituyen un atajo frente a la presión creciente sobre las desigualdades y las opresiones de clase. Así, desde arriba, uno de los golpes de efecto que observamos en el programa estudiado (sin objetar el impacto favorable que produce en las condiciones vitales de sus beneficiarios) es la disminución de los costos sociales que implicarían iniciativas de compromiso social mayor. Sus cuerpos, situados en los bordes de la informalidad laboral y la desatención institucional, garantizan la provisión de servicios que consolidan la disposición de una sociedad asegurada de trasformaciones en función de circuitos financieros y de consumo (ligados a estrategias implementadas por el propio Estado) que sustentan una política de inclusión asociada estratégicamente a la dinámica de acumulación.

En definitiva, en el doble lugar señalado hasta aquí -compuesto por la capitalización del cuerpo y la expoliación desde el consumo, que se inscriben, a su vez, en la carne como percepción y emoción, y entrega y sacrificio hacia el orden-, encontramos una combinación ajustada entre condiciones de expulsión en la pobreza y el trabajo impuesto como 
necesidad de subsistencia. El anclaje analítico en la política especificada nos ha permitido observar que la ampliación de las políticas expresa como derecho su correspondencia con fuerzas de producción y circulación, cuya trama eslabona una extensa cadena de expropiación de energías y de regulaciones activas sobre el cuerpo. No creemos que esta característica constituya una respuesta transitoria frente a los conflictos que el sistema capitalista atraviesa, sino más bien que es parte de un horizonte de cambios que (progresivamente) se disponen como mecanismo de acción y esclusa de contención frente a las posibilidades de trasformación de lo social.

\section{Referencias}

Álvarez Leguizamón, S. (2001). Capital social y concepciones de pobreza en el discurso del Banco Mundial, su funcionalidad en la "nueva cuestión social". En L. Andrenacci (Org.), La cuestión social en el Gran Buenos Aires (pp. 143-162). Buenos Aires: Universidad Nacional de General Sarmiento.

Azpiazu, D. (1988). La promoción a la inversión industrial en la Argentina. Efectos sobre la estructura industrial 1974-1987. [Documento de trabajo $\left.\mathrm{N}^{\circ} 27\right]$. Recuperado de https://repositorio.cepal.org/bitstream/handle/11362/9029/LCbueL109. pdf?sequence $=1$

Bauman, Z. (2007). Vida de consumo. Buenos Aires: Fondo de Cultura Económica.

Comisión Económica para América Latina y el Caribe, CEPAL \& Organización Internacional del Trabajo, OIT. (2019). Coyuntura laboral en América Latina y el Caribe (CEPAL). Santiago de Chile: Comisión Económica para América Latina y el Caribe. Recuperado de https://www.cepal.org/es/ publicaciones/44604-coyuntura-laboral-america-latina-caribe-futuro-trabajo-america-latina-caribe

Campos, J., Martínez, O. \& Soul, J. (2014). Acerca de la violencia laboral. Disciplinamiento patronal y nuevas formas de sufrimiento: aportes para una mirada desde los trabajadores. En L. Wacquant (Comp.), Tiempos violentos (pp. 105-123). Buenos Aires: Herramienta.

Benjamin, W. (1985). Capitalismo como religión. Gesammelte Schriften, 6, 100-103. 
Farné, S. (2016). Programas de empleo público en América Latina (Serie Macroeconomía del Desarrollo No 185). Santiago de Chile: Comisión Económica para América Latina y el Caribe. Recuperado de https://www.cepal.org/es/publicaciones/40855programas-empleo-publico-america-latina

Gobierno de la Provincia de San Luis (2004). Ley No X-0340-2004 (5385), "Seguridad Comunitaria. Régimen". Recuperado de http://www.diputados.sanluis.gov.ar

Gobierno de la Provincia de San Luis (2005). San Luis crea trabajo. Plan de inclusión. San Luis: Gobierno de la Provincia de San Luis.

Gobierno de la Provincia de San Luis (2011). Ley No XIII-0755-2011, "Enmienda de la constitución provincial incorpora artículo 11 bis". Recuperado de http://www.diputados.sanluis. gov.ar

Gobierno de la Provincia de San Luis (2018). Presupuesto plurianual 2018-2020. San Luis: Gobierno de la Provincia de San Luis.

Guinard, M. (2013). Nosotros con dignidad. San Luis: PAYNE, Gobierno de la Provincia de San Luis.

Instituto Nacional de Estadísticas y Censos (INDEC), Ministerio de Economía de Argentina. Recuperado de https://www.indec. gob.ar/

Kessler, G. (2014). Controversias sobre la desigualdad. Argentina 20032013. Buenos Aires: Fondo de Cultura Económica.

Lombardía, M. L. \& Rodríguez, K. (2015). La experiencia argentina en políticas de transferencias monetarias durante la última década. [Documento de trabajo $\mathrm{N}^{\circ}$ ]]. Buenos Aires: Ministerio de Economía.

Longou Díaz, G. \& Forteza, P. (2011). Los principales programas de protección social en la provincia de San Luis. [Documento de Trabajo No 63]. Buenos Aires: Centro de Implementación de Políticas Públicas para la Equidad y el Crecimiento. Recuperado de https://www.cippec.org/publicacion/los-principales-programas-de-proteccion-social-en-la-provincia-de-san-luis/

Mario, A. (2010). El modelo productivo de San Luis: ¿otro país es posible? En J. A. Roccatagliata (Coord.), Región Nuevo Cuyo: Desarrollo sustentable con equidad (s/r). Buenos Aires: Fundación Hernandarias, Academia Nacional de Geografía. 
Ministerio de Hacienda. (2018). Informes productivos provinciales. San Luis. Marzo 2018. Recuperado de https://www.argentina. gob.ar/sites/default/files/informe_productivo_san_luis.pdf

Schvarzer, J. (1987). Promoción industrial en Argentina. Características, evolución y resultados. Buenos Aires: Centro de Investigaciones Sociales sobre el Estado y la Administración (CISEA).

Sennett, R. (2012). La corrosión del carácter. Buenos Aires: Anagrama.

Seveso, E. (2014). Sobre los estudios de la pobreza en América Latina: hacia un examen holístico de las experiencias. Pacarina del Sur, (18), s/p. Recuperado de http://www.pacarinadelsur. com/home/abordajes-y-contiendas/881-sobre-los-estudios-de-la-

Seveso, E. (2015). Sensibilidad y pobreza. Acerca de las clases medias, las políticas de asistencia y seguridad (San Luis 2004-2010). Rosario: Puño y Letra. Disponible en https://ideologiayconflicto.wordpress.com/biblioteca/

Seveso, E. (2016). En el Sur: ¿Conocimiento para qué? Preludio a un número sobre capitalismo, conflicto y sensibilidades. Fundamentos en Humanidades, (29), 7-18. Recuperado de https://www.redalyc.org/articulo.oa?id=18447748001

Seveso, E. (2018). Ciudad, seguridad y territorio: tendencias de estructuración en San Luis (2004-2017). Revista Trabajo y Sociedad, (31), 103-126. Recuperado de https://www.unse.edu. ar/trabajoysociedad/31\%20SEVESO\%20EMILIO\%20seguridad,\%20ciudad,\%20territorio,\%20San\%20Luis.pdf

Suárez Godoy, E. (2004). San Luis... una política social diferente. San Luis: PAYNE, Gobierno de la Provincia de San Luis.

Valles, M. (1999). Técnicas cualitativas de investigación social. Reflexión metodológica y práctica profesional. Madrid: Síntesis Sociológica.

Wacquant, L. (2007). Los condenados de la ciudad. Buenos Aires: Siglo XXI.

Wacquant, L. (2010). Castigar a los pobres: el gobierno neoliberal de la inseguridad social. Barcelona: Gedisa.

Weber, T. (2005). Experiencia. En M. Opitz \& E. Wizisla (Eds.), Conceptos de Walter Benjamin (pp. 479-526). Buenos Aires: Las cuarenta.

Weller, J. (Comp.). (2017). Empleo en América Latina y el Caribe. Textos seleccionados 2006-2017. Santiago de Chile: Comisión Eco- 
nómica para América Latina y el Caribe (CEPAL). Recuperado de https://www.cepal.org/es/publicaciones/42488-empleo-america-latina-caribe-textos-seleccionados-2006-2017

Williams, R. (2000). Marxismo y literatura. Barcelona: Península.

Williams, R. (2003). Palabras clave. Un vocabulario de la cultura y la sociedad. Buenos Aires: Nueva Visión.

Zibechi, R. (2010). Política y miseria. La relación entre el modelo extractivo, los planes sociales y los gobiernos progresistas. Buenos Aires: Lavaca.

Žižek, S. (1999). El acoso de las fantasías. México D. F.: Siglo XXI.

\section{Notas de prensa}

Carnaval de Rio 2013: Definen la circulación y la seguridad en el Sambódromo (10 de enero de 2013). Agencia de Noticias San Luis. Recuperado de: http://agenciasanluis.com/

Centro de Control Operativo: viaje al secreto mundo donde controlan las calles puntanas (24 de enero de 2011). El Diario la República. Recuperado de https://www.eldiariodelarepublica.com/

Crecen las ventas por el plan de inclusión social (31 de agosto de 2003). Diario la República. Recuperado de https://www.eldiariodelarepublica.com/

El lado oculto del consumo. La seguridad, otro gasto a fin de mes (3 octubre de 2010). Diario La Nación. Recuperado de http://www. lanacion.com.ar/

Policía y Seguridad Comunitaria estrechan filas por la seguridad en la terminal (18 de abril de 2008). El Diario La República. Recuperado de https://www.eldiariodelarepublica.com/

Presentaron la sexta edición del Carnaval de Río en San Luis (4 de junio de 2014). Agencia de Noticias San Luis. Recuperado de http://agenciasanluis.com/ 